\title{
Longitudinal analyses of chest radiographs from the European Carbon Black Respiratory Morbidity Study
}

\author{
M.J.A. van Tongeren*, K. Gardiner*, C.E. Rossiter\#, J. Beach*, P. Harber ${ }^{\star}$, M.J. Harrington*
}

Longitudinal analyses of chest radiographs from the European Carbon Black Respiratory Morbidity Study. M.J.A. van Tongeren, K. Gardiner, C.E. Rossiter, J. Beach, P. Harber, M.J. Harrington. C) ERS Journals Ltd 2002.

ABSTRACT: High levels of exposure to carbon black have been linked with an increased prevalence of chest radiograph abnormalities. However, it is unclear to what extent current levels of exposure in the carbon black manufacturing industry are associated with new cases of and progression in small opacities.

Longitudinal analyses were carried out on data from workers in the European carbon black manufacturing industry who provided three full-size chest radiographs sequentially between 1987-1995. All chest radiographs were independently read by three experienced readers according to the International Labour Organisation (ILO) classification.

After exclusion of participants with previous lung diseases or injuries, females, unreadable chest radiographs and from factories with a low participation rate, data from 675 workers were available for the longitudinal analyses. An association was observed between cumulative carbon black exposure and new cases of chest radiograph abnormalities (ILO category $\geqslant 1 / 0$ ) and progression in small opacities. These associations were mainly related to changes in chest radiographs from workers at one factory. A large percentage of workers with chest radiograph abnormalities reversed to normal chest films; however, after adjusting for other factors, this was not associated with levels of exposure to carbon black dust.

In conclusion, the results show that exposure to carbon black is associated with increased risk of chest radiographic abnormalities, which may be reversible after reduction or cessation of exposure.

Eur Respir J 2002; 20: 417-425.
*Institute of Occupational Health, University of Birmingham, UK. ${ }^{\#}$ Somerset West, South Africa. "Division of Occupational and Environmental Medicine, Dept of Family Medicine, University of California at Los Angeles, Los Angeles, CA, USA.

Correspondence: M.J.A. van Tongeren, Institute of Occupational Health, University of Birmingham, Edgbaston, Birmingham, B15 2TT, UK.

Fax: 441214146217

E-mail: M.J.A.van_Tongeren@bham. ac.uk

Keywords: Carbon black

chest radiographs

longitudinal analyses

occupational exposure

pneumoconiosis

Received: March 122001

Accepted after revision: March 252002

This study was funded by the International Carbon Black Association.
Carbon black is a very fine powdered form of elemental carbon and is manufactured by the controlled vapour phase pyrolysis of liquid or gaseous hydrocarbons [1]. Currently, the oil-furnace process accounts for $>95 \%$ of world production, with most of the carbon black being used in the production of automotive tyres $[2,3]$.

Concern about health effects following inhalation of carbon black has given rise to a number of occupational respiratory morbidity and mortality studies, with equivocal results [2, 4-12]. Although the primary particles of carbon black $(10-500 \mathrm{~nm})$ readily aggregate and agglomerate to larger particles, these are still submicron in aerodynamic diameter, and therefore small enough to reach the distal airways and alveoli.

A detailed review of the literature of the respiratory health effects of occupational exposure to carbon black has been published previously, suggesting that most of these studies have either methodological shortcomings or lack the necessary detail for confident interpretation of the results [2]. Most of these studies suggest that long-term exposure to carbon black can lead to some form of pneumoconiotic changes $[4,8,9$, 13-20]. However, most of these studies were small, ranging from autopsy studies and case reports to populations of $\sim 30-150$ workers. There have been four large investigations into the prevalence of pneumoconiotic abnormalities amongst workers in the carbon black manufacturing industry, each utilising ostensibly the same (European) population and involving between $\sim 1,000$ and 2,000 workers. The first of these [4] found only six workers (out of $935,<1 \%$ ) with chest radiograph abnormalities (International Labour Organisation (ILO) category $\geqslant 0 / 1)$. Three linked cross-sectional investigations in the European carbon black industry have been reported [5] (I. Saez-Llorett, Institute of Occupational Health, University of Birmingham, Birmingham, UK; personal communication). These studies found considerably higher prevalences of small opacities (between $10-20 \%$ ILO category $\geqslant 1 / 0$ ). The prevalence of small opacities was associated with indices of personal dust exposure in each of the three, linked, cross-sectional surveys [5], although the prevalence had declined at the time of the last cross-sectional phase. In addition, a sharp reduction in exposure was observed, predominantly between the first and second survey, concurrent with a decline in smoking habits. 
The studies referenced in the previous section were of a cross-sectional nature and therefore could not investigate longitudinal changes in the chest radiographs. By combining the three cross-sectional studies [5], a longitudinal cohort was established. The main aim of this paper is to investigate if current levels of exposure to carbon black are related to progressive changes in chest radiographs using the longitudinal component of these three cross-sectional studies, which covers a period of $\sim 8$ yrs. In addition, the relationship between exposure to carbon black and new cases of small opacities in Phase III will be studied. Finally, as exposure levels have dropped substantially since the first cross-sectional study $[21,22]$, this paper will investigate if the radiological changes found in the cross-sectional studies are reversible and if this is associated with exposure.

\section{Methods}

\section{Population}

Data were collected in 19 factories during three cross-sectional surveys $[5,12]$. Data for the first survey were collected between September 1987 and April 1989; for the second survey between May 1991 and April 1992; and for the third survey between April 1994 and June 1995. Persons of either sex and in full-time employment for $>1$ month were eligible to participate in the study. All participants completed self-administered questionnaires on respiratory symptoms [23], occupational history, previous occupational exposures, smoking habits and previous lung illnesses, injuries or operations.

In the first survey, 2,879 subjects participated, with chest radiographs being available for 1,942 workers. Of these, chest radiographs were available in all three surveys for 952 workers $(49 \%)$.

\section{Readings of radiographs}

Full sized chest radiographs $(40 \times 40 \mathrm{~cm})$ were taken and evaluated independently by three experienced readers using the ILO 1980 International Classification of Radiographs of Pneumoconiosis [24]. As the chest films from the first survey were evaluated initially by a different team of readers and to reduce potential reader bias over time, all chest radiographs from the first and second surveys from participants in the longitudinal study were reread simultaneously with the films from the third survey.

The films were sent to the readers in random order, but with the three films for each participant read closely together in time. The readers were blind to all factors including the sequence in which the radiographs were taken. All readers used recording clerks to ensure that each reading was complete and in accordance with the classification. Trigger films were included at random throughout each batch, and immediately after reading a trigger film, the recording clerk would inform the reader of the agreed trigger reading [25]. The readers also recorded the technical quality of the chest radiograph on a scale from 1 (good) to 4 (unacceptable). In cases where readers disagreed, the median was determined by ordering the three readings for each feature of the ILO classification and taking the middle reading.

\section{Exposure assessment}

Exposure estimates were obtained from three extensive assessment surveys that ran concurrently with the three cross-sectional studies [1, 21, 22, 26]. In total, 8,015 personal inhalable dust measurements were taken, using the Institute of Occupational Medicine sampling head with a flow rate of $2 \mathrm{~L} \cdot \mathrm{min}^{-1}$ [27]. Individual exposure estimates were obtained by calculating the arithmetic mean (AM) exposure for each combination of factory and job category. Individual cumulative exposure was calculated by multiplying the number of months employed with the exposure estimate (AM) for that job category taking into account the changes in levels of exposure since the first survey and work history.

\section{Statistical analyses}

In total, 2,856 full sized chest radiographs from 952 workers were available for analyses. All workers with previous lung injuries or operations, pleurisy, pulmonary tuberculosis and/or bronchial asthma were excluded, as were all workers from factories with participation rates in the first survey of $<60 \%$. In addition, all females were excluded as their number was small and most were administrative workers, hence, they were not exposed. Finally, workers with at least one unreadable chest radiograph were excluded.

Presence of small opacities was defined as a chest radiograph with a median reading of small opacity profusion of category $1 / 0$ or higher, using the ILO International Classification of Radiographs of Pneumoconiosis [24]. For the longitudinal analyses, progression in small opacities was defined as an increase of $\geqslant$ two ILO subcategories between the first and the third survey (e.g. from 0/1 to 1/1). Participants with normal chest radiographs in the first phase (i.e. $0 / 0$ or $0 / 1)$ but with small opacities in the third survey $(\geqslant 1 / 0)$ were defined as new cases with small opacities. Regression in small opacities was defined as a decrease of $\geqslant$ two ILO subcategories, whilst reversion was defined as changing from an abnormal chest radiograph in the first phase to a normal chest radiograph in the third survey.

Cumulative inhalable dust exposure between the first and third survey was entered into the models as a categorical variable (high, medium or low). These exposure groups were created by ranking the workers according to exposure and choosing cut-off points so that each group contained more or less equal numbers of workers (i.e. tertiles). Other exposure metrics were also considered, but these were either highly correlated with cumulative exposure between the surveys 
Table 1.-Comparison of the cross-sectional $(n=1,942)$ and longitudinal $(n=952)$ populations with chest radiographs

\begin{tabular}{|c|c|c|}
\hline & $\begin{array}{l}\text { Cross-sectional } \\
\text { survey I }\end{array}$ & $\begin{array}{l}\text { Longitudina } \\
\text { cohort }\end{array}$ \\
\hline Age yrs & 42 & 38 \\
\hline $\begin{array}{l}\text { Duration of } \\
\text { employment months }\end{array}$ & 178.0 & 162.2 \\
\hline$\%$ Females & 6.9 & 6.5 \\
\hline \% Smokers & 50.6 & 51.2 \\
\hline$\%$ Exsmokers & 27.0 & 25.9 \\
\hline $\begin{array}{l}\text { Current inhalable } \\
\mathrm{mg} \cdot \mathrm{m}^{-3}\end{array}$ & 1.6 & 1.6 \\
\hline $\begin{array}{c}\text { Cumulative inhalable } \\
\mathrm{mg} \cdot \mathrm{month} \cdot \mathrm{m}^{-3}\end{array}$ & 299.1 & 279.0 \\
\hline Small opacities ${ }^{\#}$ & 12.5 & 10.4 \\
\hline Cough $\%$ & 17.8 & 15.1 \\
\hline Sputum \% & 17.2 & 17.2 \\
\hline $\begin{array}{l}\text { Cough with } \\
\text { sputum } \%\end{array}$ & 10.1 & 9.2 \\
\hline Wheezing & 8.5 & 8.1 \\
\hline Dyspnoea $2+$ & 3.4 & 1.9 \\
\hline $\begin{array}{l}\text { Breathlessness } \\
\text { with wheezing }\end{array}$ & 3.4 & 3.2 \\
\hline Chronic bronchitis & 4.9 & 4.5 \\
\hline FVC $\%$ pred & 108.8 & 110.9 \\
\hline FEV1 $\%$ pred & 104.1 & 105.9 \\
\hline FEF $25-75 \%$ pred & 85.6 & 87.3 \\
\hline FEV1:FVC $\%$ pred & 91.4 & 91.8 \\
\hline
\end{tabular}

FVC: forced vital capacity; FEV1: forced expiratory volume in one second; FEF25-75: forced midexpiratory flow. \#: prevalence of small opacities (International Labour Organisation category $\geqslant 1 / 0$ ) given here is based upon the original survey readings.

(such as mean exposure level over the three surveys or exposure level at the first or third survey) or were thought to be estimated with unacceptable error (such as cumulative exposure prior to the first survey).

Multivariate logistic regression analyses were carried out to test if progression, regression, new cases and reversion of small opacities were related to cumulative carbon black exposure whilst adjusting for potential confounders such as smoking habits and age. For the analyses on new cases, only those workers with normal chest radiographs (ILO category $0 / 0$ or $0 / 1$ ) in the first survey were used. For the analyses on regression in and reversion of small opacities, only those with chest radiograph abnormalities (ILO category $\geqslant 1 / 0$ ) in the first survey were used.

\section{Results}

\section{Population}

The average age in the first survey of participants with chest radiographs in all three surveys (i.e. the longitudinal cohort) was 38 yrs and $51 \%$ were current smokers (table 1). The average age of the longitudinal cohort was somewhat lower than that of the total population for which chest radiographs were available in the first cross-sectional survey, whilst there was little difference in smoking habits. Some minor differences were observed in prevalence of small opacities, prevalence of respiratory symptoms and average value of the lung function parameters (table 1).

After excluding all participants with previous lung injuries or operations, pleurisy, pulmonary tuberculosis and/or bronchial asthma $(\mathrm{n}=129)$; all workers from factories with participation rates in the first survey of $>60 \% \quad(n=90)$; all females $(n=55)$; and workers with at least one unreadable chest radiograph $(n=4)$; data from 675 workers with three chest radiographs were available for the longitudinal analyses. The average age of this group was 38 yrs (range $18-59$ yrs) in the first survey, with an average duration of employment of $\sim 13$ yrs (mean 157 months, range 2-409 months) (table 2). In the first survey, $54 \%$ of the workers were current smokers and 25\% exsmokers; the percentage of current smokers dropped to $49 \%$ in the second and $46 \%$ in third survey.

\section{Dust exposure}

Mean inhalable dust exposure dropped significantly from $1.5 \mathrm{mg} \cdot \mathrm{m}^{-3}$ in the first to $0.9 \mathrm{mg} \cdot \mathrm{m}^{-3}$ in the second and $0.6 \mathrm{mg} \cdot \mathrm{m}^{-3}$ in the third survey. The mean cumulative inhalable dust exposure between the first and the third survey was $70.1 \mathrm{mg} \cdot \mathrm{month} \cdot \mathrm{m}^{-3}$, with a range of $11.1-564.8 \mathrm{mg} \cdot \mathrm{month} \cdot \mathrm{m}^{-3}$. All workers were grouped into one of three cumulative inhalable dust exposure groups. There was little difference in average age and duration of employment between the

Table 2. - Population characteristics categorised by cumulative inhalable dust exposure between the first and third survey

\begin{tabular}{|c|c|c|c|c|}
\hline & \multirow[b]{2}{*}{ All } & \multicolumn{3}{|c|}{ Cumulative inhalable dust exposure between phase I and III } \\
\hline & & Low & Medium & High \\
\hline Subjects $n$ & 675 & 225 & 232 & 218 \\
\hline Age & $38(9)$ & $38(9)$ & $39(8)$ & $37(9)$ \\
\hline Duration of employment & $13.1(8.1)$ & $13.1(8.7)$ & $14.2(7.8)$ & $11.7(7.6)$ \\
\hline Smokers in phase I \% & 53.6 & 43.3 & 57.1 & 60.4 \\
\hline Smokers in phase III \% & 46.2 & 33.3 & 57.1 & 53.0 \\
\hline $\begin{array}{c}\text { Cumulative dust exposure } \\
\mathrm{mg} \cdot \mathrm{month} \cdot \mathrm{m}^{-3} \text { (range) }\end{array}$ & $70.1(11.1-564.9)$ & $20.4(11.1-30.6)$ & $54.8(31.5-79.1)$ & $137.8(82.1-564.9)$ \\
\hline
\end{tabular}

Data are presented as mean (SD) unless otherwise stated. 
Table 3. - Median International Labour Organisation (ILO) profusion category by phase and the percentage of radiographs with a median ILO category of $\geqslant 1 / 0$ (males only)

\begin{tabular}{|c|c|c|c|c|c|c|}
\hline & \multicolumn{2}{|c|}{ Phase I } & \multicolumn{2}{|c|}{ Phase II } & \multicolumn{2}{|c|}{ Phase III } \\
\hline & $\mathrm{n}$ & $\%$ & $\mathrm{n}$ & $\%$ & $\mathrm{n}$ & $\%$ \\
\hline $0 / 0$ & 372 & 55.1 & 353 & 52.3 & 328 & 48.6 \\
\hline 0/1 & 209 & 31.0 & 188 & 27.9 & 214 & 31.7 \\
\hline $1 / 0$ & 56 & 8.3 & 86 & 12.7 & 79 & 11.7 \\
\hline $1 / 1$ & 35 & 5.2 & 42 & 6.2 & 45 & 6.7 \\
\hline $1 / 2$ & 1 & 0.1 & 4 & 0.6 & 4 & 0.6 \\
\hline $2 / 1$ & 1 & 0.1 & & & 3 & 0.4 \\
\hline $2 / 2$ & 1 & 0.1 & 2 & 0.3 & 2 & 0.3 \\
\hline$\geqslant 1 / 0$ & 94 & 13.9 & 134 & 19.9 & 133 & 19.7 \\
\hline
\end{tabular}

exposure groups, but there were fewer smokers in the low exposed group (table 2).

\section{Prevalence of small opacities}

The majority of the film quality of these chest radiographs was classified as acceptable (film quality 2 ), whilst the percentage of poor films (film quality 3 ) increased from $3.5 \%$ in the first to $6.9 \%$ in the third survey. The prevalence of small opacities (ILO category $\geqslant 1 / 0$ ) was $13.9 \%$ in the first survey, rising to $19.9 \%$ in the second and $19.7 \%$ in the third survey (table 3); with the majority of the opacities being irregular in all three surveys (predominant shape/size was $t$ (small irregular opacities with a width $1.5-3 \mathrm{~mm}$ )). The number of workers with small opacities of ILO category $\geqslant 1 / 2$ increased from three in the first survey to nine in the third survey. Of these nine workers, one had a forced vital capacity (FVC) which was $<90 \%$ of predicted when using the equations derived from the European Coal and Steel Community [28], and one could not produce a valid spirometry trace according to the criteria of the American Thoracic Society [29]. Five of these nine workers reported working with asbestos in either their current or previous jobs.

The majority of the increase in prevalence of small opacities was found in participants from factory 10 (fig. 1). In fact, if this factory was excluded from the analyses, the prevalence of small opacities would have been relatively stable across the three surveys $(11.7 \%$, $13.6 \%$ and $11.0 \%$, respectively).

\section{Progression and new cases of small opacities}

Progression of at least two ILO subcategories between the first and third survey was observed in 43 workers $(6.4 \%)$. The majority of progression $(90 \%)$ was from ILO subcategory $0 / 0$ to $1 / 0$ or from $0 / 1$ to $1 / 1$. Only four cases of existing chest radiograph abnormalities progressed to higher ILO categories; two from $1 / 0$ to $1 / 2$ and two from $1 / 1$ to $2 / 2$.

Significant differences were found in progression of small opacities between cumulative inhalable dust exposure groups (Chi-squared 9.2; $\mathrm{p}=0.010$ ) (table 4).

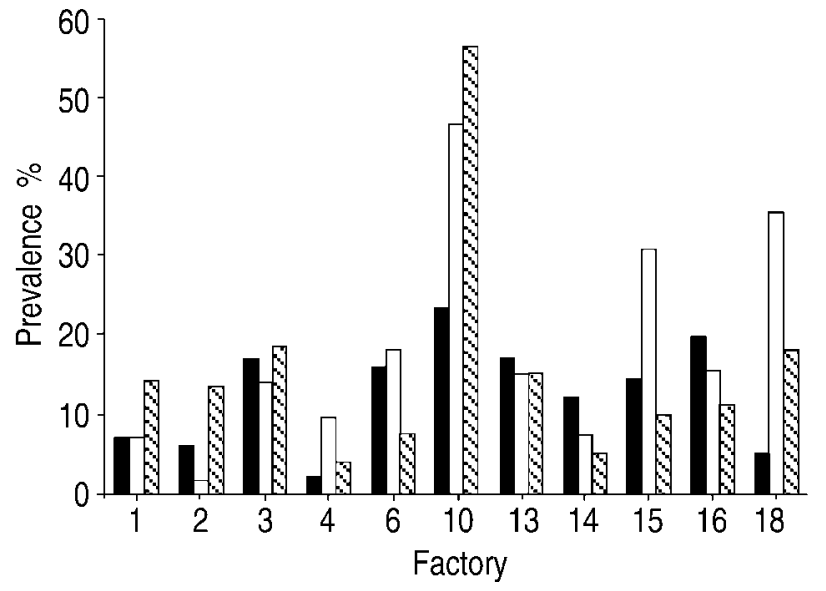

Fig. 1.- Prevalence with small opacities of International Labour Organisation $\geqslant 1 / 0$ by survey and factory. $\mathbf{\square}$ : survey I; $\square$ : survey II; $\mathbb{\$}$ : survey III.

Smoking status also appeared to be a significant predictor of progression in small opacities, with $2.1 \%$ in the nonsmokers, $4.0 \%$ in the exsmokers and $9.9 \%$ in the current smokers (Chi-squared 12.9; $\mathrm{p}=0.002$ ). No significant differences in progression of small opacities were found for self-reported asbestos exposure, previous dusty occupations, birth decades, or for median chest radiograph reading in the first survey. However, significant differences were found between the film quality, with $16.7 \%$ of those workers with a poor quality chest radiograph having progression of $\geqslant$ two ILO subcategories. Chi-squared tests showed that factory was a strong predictor of progression in small opacities (Chi-squared 81.7; $\mathrm{p}<0.001$ ), with the majority of subjects with progression coming from factory $10(23 \%$ of workers in factory 10 , compared with $2 \%$ in the remaining factories).

Out of 581 workers with a normal chest radiograph in the first survey, 77 workers $(13.3 \%)$ had chest radiograph abnormalities $(\geqslant 1 / 0)$ in the third survey. Again, the majority of these came from factory 10 ( $45 \%$ of workers in factory 10 , compared with $6.7 \%$ in the remaining factories) (Chi-squared 113.4; $\mathrm{p}<0.001$ ). Chi-squared tests showed statistical significant associations between new cases of small opacities and cumulative inhalable dust exposure (Chi-squared 24.3; $\mathrm{p}<0.001$ ), smoking status in the third survey (Chisquared 16.1; $\mathrm{p}<0.001)$, ILO-category in first survey (Chi-squared 35.3; $\mathrm{p}<0.001$ ) and film quality in the first survey (Chi-squared 21.1; $\mathrm{p}<0.001$ ) (table 4). For the cumulative exposure groups, new cases of small opacities occurred in $4.3 \%$ in the low, $16.4 \%$ in the medium and $20.5 \%$ in the high exposed group, respectively.

Table 5 shows the results of multiple logistic regression analyses for progression in ILO subcategory and new cases of small opacities. Smoking and cumulative inhalable dust exposure were statistically significantly associated with progression of $\geqslant$ two ILO subcategories, whilst film quality was of borderline statistical significance $(p=0.067)$. The odds ratio $(O R)$ for the highest cumulative exposure group was $3.1(\mathrm{p}=0.017)$ and for the medium exposure group 2.1 ( $\mathrm{p}=0.141)$. 
Table 4. - Results of univariate analyses on progression of $\geqslant 2$ International Labour Organisation (ILO) categories on chest radiographs or new cases of small opacities for various exposure indices

\begin{tabular}{|c|c|c|c|c|c|c|c|c|}
\hline & \multicolumn{4}{|c|}{ Progression } & \multicolumn{4}{|c|}{ New cases } \\
\hline & $\mathrm{n}$ & $\%$ & $\chi^{2}$ & p-value & $\mathrm{n}$ & $\%$ & $\chi^{2}$ & $\mathrm{p}$-value \\
\hline \multicolumn{9}{|l|}{ Cum. Inh. survey I-III } \\
\hline Low $\left(<31 \mathrm{mg} \cdot \mathrm{month} \cdot \mathrm{m}^{-3}\right)$ & 225 & 2.7 & \multirow{3}{*}{9.2} & \multirow{3}{*}{0.010} & 210 & 4.3 & \multirow{3}{*}{24.3} & \multirow{3}{*}{$<0.001$} \\
\hline Medium $\left(31-80 \mathrm{mg} \cdot \mathrm{month} \cdot \mathrm{m}^{-3}\right)$ & 232 & 6.9 & & & 195 & 16.4 & & \\
\hline High $\left(>80 \mathrm{mg} \cdot \mathrm{month} \cdot \mathrm{m}^{-3}\right)$ & 218 & 9.6 & & & 176 & 20.5 & & \\
\hline \multicolumn{9}{|l|}{ Duration of employment $\mathrm{t}^{\#}$} \\
\hline Low $(<103$ months $)$ & 226 & 5.8 & \multirow{3}{*}{1.5} & \multirow{3}{*}{0.465} & 205 & 13.7 & \multirow{3}{*}{2.6} & \multirow{3}{*}{0.274} \\
\hline Medium (103-205 months) & 225 & 8.0 & & & 190 & 15.8 & & \\
\hline High ( $>205$ months) & 224 & 5.4 & & & 186 & 10.2 & & \\
\hline \multicolumn{9}{|l|}{ Smoking survey III } \\
\hline Never & 140 & 2.1 & \multirow{3}{*}{12.9} & \multirow{3}{*}{0.002} & 129 & 5.4 & \multirow{3}{*}{16.1} & \multirow{3}{*}{$<0.001$} \\
\hline Ex & 223 & 4.0 & & & 191 & 10.5 & & \\
\hline Current & 312 & 9.9 & & & 261 & 19.2 & & \\
\hline \multicolumn{9}{|l|}{ Year of birth } \\
\hline$<1940$ & 120 & 6.7 & \multirow{4}{*}{0.7} & \multirow{4}{*}{0.862} & 104 & 12.5 & \multirow{4}{*}{1.1} & \multirow{4}{*}{0.770} \\
\hline $1940-1949$ & 250 & 7.2 & & & 201 & 14.9 & & \\
\hline $1950-1959$ & 192 & 5.2 & & & 168 & 11.3 & & \\
\hline$>1959$ & 113 & 6.2 & & & 108 & 13.9 & & \\
\hline \multicolumn{9}{|l|}{ Asbestos exposure (self-reported) } \\
\hline No & 466 & 6.2 & \multirow[t]{2}{*}{0.1} & \multirow[t]{2}{*}{0.815} & 409 & 12.7 & \multirow[t]{2}{*}{0.3} & \multirow[t]{2}{*}{0.555} \\
\hline Yes & 209 & 6.7 & & & 172 & 14.5 & & \\
\hline Dust exposure (self-reported) & & & & & & & & \\
\hline No $T-19$ & 473 & 6.1 & 0.2 & 0.697 & 413 & 12.3 & 1.0 & 0.313 \\
\hline Yes & 202 & 6.9 & & & 168 & 15.5 & & \\
\hline ILO reading in survey I & & & & & & & & \\
\hline $0 / 0,0 / 1$ & 581 & 6.7 & 0.8 & 0.365 & & & & \\
\hline$\geqslant 1 / 0$ & 94 & 4.3 & & & & & & \\
\hline ILO reading in survey I & & & & & & & & \\
\hline $0 / 0$ & & & & & 372 & 7.0 & 35.3 & $<0.001$ \\
\hline $0 / 1$ & & & & & 209 & 24.4 & & \\
\hline Film quality survey I & & & & & & & & \\
\hline Good & 65 & 0.0 & & & 64 & 0.0 & & \\
\hline Acceptable & 586 & 6.7 & 8.8 & 0.012 & 496 & 13.9 & 21.2 & $<0.001$ \\
\hline Poor & 24 & 16.7 & & & 21 & 38.1 & & \\
\hline
\end{tabular}

$\chi^{2}$ : Chi-squared test; Cum. Inh. survey I-III: cumulative inhalable dust exposure between the first and third survey. ${ }^{\#}$ : duration of employment in the first survey.

Workers with an ILO reading in the first survey of $0 / 1$ were more than three times more likely to have abnormal chest radiographs in the third survey compared to those with a reading of $0 / 0$ in the first survey (table 5). Again, smoking and cumulative inhalable dust exposure were statistically significant predictors of new small opacities. Compared to the low exposure group, the medium exposed group had an OR of $3.5(\mathrm{p}=0.002)$ and the high exposed group an OR of $4.6(\mathrm{p}<0.001)$.

\section{Regression and reversion of small opacities}

The analyses of regression in and reversion of small opacities were limited to those workers with a median ILO category in the first survey of $\geqslant 1 / 0$ (i.e. those who have the opportunity to regress) $(n=94)$. Of these workers, 13 had median readings that were at least two ILO subcategories lower in the third compared to the first survey. Chi-squared tests revealed significant associations between regression and year of birth and film quality in the first survey, although the
Chi-squared test may not be valid due to small numbers (i.e. $<5)$ in some of the cells (table 6).

Of the 94 workers with abnormal chest radiographs in the first survey, $38(40.4 \%)$ had normal chest films in the third survey. Chi-squared tests indicated that this reversal of chest radiograph abnormality was associated with cumulative dust exposure, smoking status and ILO reading in the first survey (table 6). Reversal of abnormality occurred in $73.3 \%$ of subjects in the low, $32.4 \%$ in the medium and $35.7 \%$ in the high exposed group (Chi-squared 8.1; $\mathrm{p}=0.017$ ). These percentages were $72.7 \%$ for nonsmokers, $46.9 \%$ for exsmokers and $29.4 \%$ for current smokers, respectively (Chi-squared 7.9; $\mathrm{p}=0.019$ ). For those with a median reading of $1 / 0$ in the first survey, the probability of reversal in Phase III was 57.1\% compared with $15.8 \%$ for those with median readings of $\geqslant 1 / 1$ (Chi-squared $16.1 ; \mathrm{p}<0.001)$.

Results of multiple logistic regression analyses are presented in table 7. High ORs for regression and reversion were found for nonsmokers, young workers and for workers with an ILO subcategory in the first survey of $1 / 0$ (compared with those with ILO 
Table 5.-Results of multiple logistic regression models with progression of $\geqslant 2$ International Labour Organisation (ILO) categories or new cases of small opacities as dependent variables

\begin{tabular}{|c|c|c|c|c|}
\hline & \multicolumn{2}{|c|}{ Progression } & \multicolumn{2}{|c|}{ New cases } \\
\hline & OR & $\mathrm{CI}$ & OR & CI \\
\hline \multicolumn{5}{|l|}{ Smoking } \\
\hline Non & & & & \\
\hline Ex & 1.7 & $0.5-6.5$ & 1.5 & $0.6-3.9$ \\
\hline Current & 4.1 & $1.2-13.9$ & 2.6 & $1.1-7.0$ \\
\hline \multicolumn{5}{|l|}{ Film quality in survey I } \\
\hline Good/acceptable & & & & \\
\hline Poor & 3.0 & $0.9-9.4$ & 2.5 & $0.9-7.0$ \\
\hline \multicolumn{5}{|l|}{ ILO category survey I } \\
\hline $0 / 1$ & & & 3.5 & $2.0-5.9$ \\
\hline \multicolumn{5}{|l|}{ Cum. Inh. survey I-III } \\
\hline $\begin{array}{l}\text { Medium } \\
\left(31-80 \mathrm{mg} \cdot \mathrm{month} \cdot \mathrm{m}^{-3}\right)\end{array}$ & 2.1 & $0.8-5.5$ & 3.5 & $1.6-7.6$ \\
\hline $\begin{array}{l}\text { High } \\
\left.\qquad>80 \mathrm{mg} \cdot \mathrm{month} \cdot \mathrm{m}^{-3}\right)\end{array}$ & 3.1 & $1.2-8.0$ & 4.6 & $2.1-10.0$ \\
\hline
\end{tabular}

OR: odds ratio; CI: 95\% confidence interval; Cum. Inh. survey I-III: cumulative inhalable dust exposure between the first and third survey. subcategory $\geqslant 1 / 1)$. Elevated ORs for regression and reversion were also found for low exposed workers, but these were not statistically significantly different from unity (table 7).

Significant differences were found between the factories, with only two of the 30 subjects $(6.7 \%)$ in factory 10 with chest radiograph abnormalities in the first survey reverting to normal; for the remaining factories this was $56 \%$.

\section{Discussion}

This paper describes the results of longitudinal analyses of chest radiographs from a large study of workers in the carbon black manufacturing industry in Europe. Previously, statistically significant associations between occupational dust exposure in this industry and increased prevalence of small opacities have been reported [5]. However, these reports also showed that, after an initial increase, the prevalence of abnormal chest radiographs declined during the last two cross-sectional surveys, whilst exposure levels and smoking habits also decreased (I. Saez-Llorett; personal communication).

The prevalence of small opacities in the longitudinal

Table 6. - Results of univariate analyses on regression in International Labour Organisation (ILO) score of $\geqslant 2$ categories or on reversion on small opacities for various exposure indices

\begin{tabular}{|c|c|c|c|c|c|c|c|c|}
\hline & \multicolumn{4}{|c|}{ Regression } & \multicolumn{4}{|c|}{ Reversion } \\
\hline & $\mathrm{n}$ & $\%$ & $\chi^{2}$ & p-value & $\mathrm{n}$ & $\%$ & $\chi^{2}$ & p-value \\
\hline \multicolumn{9}{|l|}{ Cum. Inh. survey I-III } \\
\hline Low $\left(<31 \mathrm{mg} \cdot \mathrm{month} \cdot \mathrm{m}^{-3}\right)$ & 15 & 26.7 & \multirow{3}{*}{2.7} & \multirow{3}{*}{0.255} & 15 & 73.3 & \multirow{3}{*}{8.1} & \multirow{3}{*}{0.017} \\
\hline Medium $\left(31-80 \mathrm{mg} \cdot \mathrm{month} \cdot \mathrm{m}^{-3}\right)$ & 37 & 13.5 & & & 37 & 32.4 & & \\
\hline High $\left(>80 \mathrm{mg} \cdot \mathrm{month} \cdot \mathrm{m}^{-3}\right)$ & 42 & 9.5 & & & 42 & 35.7 & & \\
\hline \multicolumn{9}{|l|}{ Duration of employment ${ }^{\#}$} \\
\hline Low ( $<103$ months) & 21 & 23.8 & \multirow{3}{*}{2.9} & \multirow{3}{*}{$0.236^{\bullet}$} & 21 & 42.9 & \multirow{3}{*}{0.1} & \multirow{3}{*}{0.966} \\
\hline Medium (103-205 months) & 35 & 14.3 & & & 35 & 40.0 & & \\
\hline High ( $>205$ months) & 38 & 7.9 & & & 38 & 39.5 & & \\
\hline \multicolumn{9}{|l|}{ Smoking status in survey III } \\
\hline Never & 11 & 27.3 & \multirow{3}{*}{2.4} & \multirow{3}{*}{$0.294^{\bullet}$} & 11 & 72.7 & \multirow{3}{*}{7.9} & \multirow{3}{*}{0.019} \\
\hline Ex & 32 & 15.6 & & & 32 & 46.9 & & \\
\hline Current & 51 & 9.8 & & & 51 & 29.4 & & \\
\hline \multicolumn{9}{|l|}{ Year of birth } \\
\hline$<1950$ & 29 & 20.7 & \multirow[t]{2}{*}{9.5} & \multirow[t]{2}{*}{$0.023^{\bullet}$} & 16 & 25.0 & & \\
\hline$>1950$ & 65 & 10.8 & & & 49 & 42.9 & 5.0 & 0.169 \\
\hline \multicolumn{9}{|l|}{ Asbestos exposure (self-reported) } \\
\hline No & 57 & 17.5 & \multirow[t]{2}{*}{1.7} & \multirow[t]{2}{*}{$0.195^{\bullet}$} & 57 & 43.9 & \multirow[t]{2}{*}{0.7} & \multirow[t]{2}{*}{0.400} \\
\hline Yes & 37 & 8.1 & & & 37 & 35.1 & & \\
\hline \multicolumn{9}{|l|}{ Dust exposure (self-reported) } \\
\hline No & 60 & 10.0 & \multirow[t]{2}{*}{2.0} & \multirow{2}{*}{$0.153^{\bullet}$} & 60 & 38.3 & \multirow[t]{2}{*}{0.3} & \multirow[t]{2}{*}{0.583} \\
\hline Yes & 34 & 20.6 & & & 34 & 44.1 & & \\
\hline ILO reading in survey I & & & & & & & & \\
\hline $1 / 0$ & 56 & 12.5 & 0.2 & 0.650 & 56 & 57.1 & 16.1 & $<0.001$ \\
\hline$\geqslant 1 / 1$ & 38 & 15.8 & & & 38 & 15.8 & & \\
\hline Film quality survey I & & & & & & & & \\
\hline Good & 1 & 100.0 & & & 1 & 100.0 & & \\
\hline Acceptable & 90 & 13.3 & 6.7 & $0.035^{\bullet}$ & 90 & 38.9 & 2.4 & $0.298^{\top}$ \\
\hline Poor & 3 & 0.0 & & & 3 & 66.7 & & \\
\hline
\end{tabular}

$\chi^{2}$ : Chi-squared test; Cum. Inh. survey I-III: cumulative inhalable dust exposure between the first and third survey. $\#$ : duration of employment in the first survey; $"$ : in some of the cells the expected number of observations is $<5$ and therefore the Chi-squared test may not be valid. 
Table 7. - Results of multiple logistic regression models with regression of $\geqslant 2$ (International Labour Organisation) (ILO) categories or reversion of small opacities as dependent variables

\begin{tabular}{|c|c|c|c|c|}
\hline & \multicolumn{2}{|c|}{ Regression } & \multicolumn{2}{|c|}{ Reversion } \\
\hline & OR & $\mathrm{CI}$ & OR & $\mathrm{CI}$ \\
\hline \multicolumn{5}{|l|}{ Smoking status in survey I } \\
\hline Non & 4.5 & $0.7-29.5$ & 11.3 & $1.7-75.5$ \\
\hline Ex & 2.3 & $0.5-10.4$ & 2.0 & $0.7-5.8$ \\
\hline Current & & & & \\
\hline \multicolumn{5}{|l|}{ Year of Birth } \\
\hline$<1940$ & & & & \\
\hline 1940-1949 & 1.3 & $0.2-8.6$ & 3.2 & $0.6-16.1$ \\
\hline $1950-1959$ & 1.5 & $0.2-12.0$ & 2.8 & $0.5-17.0$ \\
\hline$>1959$ & 11.2 & $0.9-142.9$ & 21.1 & $1.3-354.5$ \\
\hline Asbestos exposure (self-reported) & 0.6 & $0.1-3.0$ & & \\
\hline Dust exposure (self-reported) & 2.3 & $0.6-8.5$ & & \\
\hline \multicolumn{5}{|l|}{ ILO category in survey I } \\
\hline $\begin{array}{l}1 / 0 \\
>1 / 0\end{array}$ & & & 7.1 & $2.2-23.1$ \\
\hline \multicolumn{4}{|l|}{ Cum. Inh. survey I-III } & \\
\hline Low $\left(<31 \mathrm{mg} \cdot\right.$ month $\left.\cdot \mathrm{m}^{-3}\right)$ & & $0.4-7.6$ & 1.6 & $0.5-5.6$ \\
\hline Medium $\left(31-80 \mathrm{mg} \cdot \mathrm{month} \cdot \mathrm{m}^{-3}\right)$ & 0.7 & $0.1-5.3$ & $\begin{array}{l}1.0 \\
1.4\end{array}$ & $\begin{array}{l}0.5-5.0 \\
0.4-4.9\end{array}$ \\
\hline $\operatorname{High}\left(>80 \mathrm{mg} \cdot \mathrm{month} \cdot \mathrm{m}^{-3}\right)$ & & & & \\
\hline
\end{tabular}

OR: odds ratio; CI: 95\% confidence interval; Cum. Inh. survey I-III: cumulative inhalable dust exposure between the first and third survey.

cohort varied between $14-20 \%$ over the study period. The predominant shape of the opacities was irregular, which is in contrast with the findings from GARDINER et al. [5] who reported that the predominant primary shape was rounded, and with the study by CROSBIE [4] who only reported rounded opacities. The prevalence of small opacities in the longitudinal cohort was somewhat higher than that reported for all participants in the first $(9.9 \%)$ [5] and third cross-sectional survey $(9.7 \%)$, but similar to the prevalence in the second survey (19.1\%) (I. Saez-Llorett; personal communication). The differences are due partly to the fact that factory 10 , which had a high prevalence of small opacities, was not included in the crosssectional analyses of the first and third survey, as the participation rate in these surveys was $<60 \%$ for this factory. However, shortly after completion of the first survey, additional chest radiographs were received from factory 10 , which increased the participation rate to $>60 \%$, and therefore allowing for the inclusion of this factory in the longitudinal analyses (note: only the participation rate in the first cross-sectional survey was part of the inclusion criteria for the longitudinal study and not the participation rates in the subsequent cross-sectional surveys). In addition, the initial readings of the first cross-sectional survey cannot be compared directly with results presented here as all films from the first survey have been reread by different readers.

Multiple logistic regression analyses showed an association between recent cumulative dust exposure and new cases of chest radiograph abnormalities (ILO category $\geqslant 1 / 0$ ) and progression in small opacities. Estimates of cumulative inhalable dust rather than respirable dust were used in the longitudinal analyses, even though data on respirable dust were available. Due to the relatively low dust concentrations it was felt that inhalable dust exposure was assessed with more precision due to the collection of more material on the filters. In addition, inhalable and respirable dust concentrations were highly correlated in this industry.

Other factors associated with progression were smoking, chest radiograph reading in the first survey and quality of chest radiograph. Film quality could, through its link with obesity, be a marker for unhealthy lifestyle, which may explain the link with progression in small opacities. New cases of chest radiograph abnormalities and workers with progression in small opacities had significantly lower percentage of predicted forced expiratory volume in the first second of expiration (FEV1) in the third compared to the first survey. The FVC remained unchanged. Obstructive airflow disorders (e.g. chronic obstructive pulmonary disease) may be associated with decreased clearance and increased retention of carbon black and other particles as shown for other dusts. This may explain why FEV1 and not FVC appear to be related to progression.

Few cases of progression to higher ILO category opacities $(\geqslant 1 / 2)$ were observed during this study and it is unclear if the progression in these cases was due to carbon black exposure.

Reversion of chest radiograph abnormality occurred in $38 \%$ of all participants with small opacities in the first survey. This was associated with smoking status, year of birth and initial chest radiograph reading. After adjusting for these factors, no significant association was found with dust exposure. However, these analyses were of very limited power due to the small number of workers $(n=94)$. Regression in small opacities or reversion of chest radiograph abnormalities did not have a statistically significant effect on the lung function parameters. Apart from environmental and lifestyle factors, the underlying cause of 
regression in the small opacities and reversion of chest radiograph could be a regression to the mean.

Large differences in longitudinal effects in the chest radiographs were observed between the factories. Significantly more progression and new cases of chest radiograph abnormalities were observed in factory 10 compared to the other factories. Factory 10 still exploits the lamp and channel black methods of production, which can give rise to relatively high exposures to airborne particulates of different size and physiochemical properties [30]. Exposure levels were significantly higher for the participants in factory 10 compared to the exposure levels from participants in other factories and more workers smoked in factory 10 .

In addition, the difference between factory 10 and the other factories may be attributable in part to some selection bias in factory 10 . Only $33 \%$ of the participants of the first phase from this factory were included in the longitudinal analyses compared with $53-82 \%$ from the other factories.

When observations from factory 10 were excluded from the analyses, no statistically significant associations were found between exposure and progression in or new cases of small opacities. However, this could be due simply to the limited power of the study with the loss of a large proportion of the subjects.

In conclusion, the longitudinal analyses presented in this paper show an association between the recent cumulative dust exposure and progression in small opacities and new cases of small opacities, although only a few cases of progression to higher International Labour Organisation categories were observed. It is unlikely that any shadowing on radiographs is simply deposited carbon black as phantom studies showed that a thickness of $2-3 \mathrm{~cm}$ was required before being evident on radiographic plates [31]. Workers in the carbon black industry with small opacities on the chest radiographs had lower lung function (forced vital capacity) than those with normal chest radiographs (I. Saez-Llorett; personal communication), raising the possibility of some tissue interaction. This interaction could be due to the ultrafine nature of the primary carbon black particles, as it has been shown that very fine carbon black particles have a greater potency to cause inflammatory reactions in lung tissue compared to larger particles sizes [32, 33]. However, it is unclear if this is also the case for airborne carbon black particles as the primary particles are generally agglomerated and aggregated in much larger particles.

Acknowledgements. The authors would like to thank A. Cockcroft, I. Coutts, H. Thomas, the late J. Gilson and G. Sheers for reading all chest radiographs for this study. A special thanks goes to J. Tucker for management of the project.

\section{References}

1. Gardiner K, Trethowan NW, Harrington JM, Calvert IA, Glass DC. Occupational exposure to carbon black in its manufacture. Ann Occup Hyg 1992; 36: 477-496.
2. Gardiner K. Effects on respiratory morbidity of occupational exposure to carbon black: A review. Arch Environ Health 1995; 50: 44-60.

3. International Agency for Research on Cancer. IARC monographs on the evaluation of carcinogenic risks to humans. Volume 65. Printing Processes and Printing Inks, Carbon Black and Some Nitro Compounds. International Agency for Research on Cancer. Lyon, France, World Health Organization, 1996.

4. Crosbie WA. The respiratory health of carbon black workers. Arch Environ Health 1986; 41: 346-353.

5. Gardiner K, Trethowan NW, Harrington JM, Rossiter CE, Calvert IA. Respiratory health effects of carbon black. A survey of European carbon black workers. Br J Ind Med 1993; 50: 1082-1096.

6. Küpper HU, Breitstadt R, Ulmer WT. Pulmonary function testing among employees exposed to carbon black. Appl Occup Environ Hyg 1996; 11: 954-961.

7. Küpper HU, Breitstadt R, Ulmer WT. Effects on the lung function of exposure to carbon black dusts. Results of a study carried out on 677 members of staff of the DEGUSSA factory in Kalscheuren/Germany. Int Arch Occup Environ Health 1996; 68: 478-483.

8. Szozda R. Condition of the respiratory system in workers involved in the carbon black production. Medycyna Pracy 1994; 45: 57-61.

9. Szozda R. Pneumoconiosis in carbon black workers. Sangyo Ika Daigaku Zasshi 1996; 18: 223-228.

10. Hodgson JT, Jones RD. A mortality study of carbon black workers employed at five United Kingdom factories between 1947 and 1980. Arch Environ Health 1985; 40: 261-268.

11. Parent M-E, Siemiaticky J, Renaud G. Case-control study of exposure to carbon black in the occupational setting and risk of lung cancer. Am J Ind Med 1996; 30: 285-292.

12. Gardiner K, van Tongeren MJA, Harrington JM. Respiratory health effects from exposure to carbon black: Results of the Phase II and III cross-sectional studies in the European carbon black manufacturing industry. Occup Environ Med 2001; 58: 496-503.

13. Miller AA, Ramsden F. Carbon pneumoconiosis. $\mathrm{Br}$ $J$ Ind Med 1961; 18: 103-113.

14. Kareva AI, Kollo RM. Roentgenological changes in the lungs under the effect of carbon black. Vestnik Rengenologii i Radiologii 1961; 36: 40-42.

15. Komavora LT, Rapis BL. Some indexes on the condition of the respiratory organs in carbon black plant workers. Nauchnye Trudy Omskogo Meditsinskogo Institut 1968; 86: 144-149.

16. Slepicka J, Eisler L, Mirejovski P, Simecek R. Lung changes in workers due to long-term employment in the production of carbon black. Pracovni Lekarstvi 1970; 22: 276-281.

17. Troitskaya NA, Velichkovskii BT, Bikmullina SK, Sazhina TG, Gordnova NV. Establishment of the maximum permissible concentration of ferrous industrial carbon black dust in the air of manufacturing enterprises. Gigiena Truda i Professionalnye Zabolevaniia 1975; 3: 32-36.

18. Valic F, Beritic-Stahuljak D, Mark B. A follow-up of functional and radiological lung changes in carbonblack exposure. Int Arch Arbeitsmed 1975; 34: 51-63.

19. Cocarla A, Cornea G, Dengel H, Gabor S, Milea M, Papilian VV. Carbon black pneumoconiosis. Int Arch Occup Environ Health 1976; 36: 217-228.

20. Beritic-Stahuljak D, Cigula M, Rubala D, Valic F, 
Mark B. Follow-up study of lung changes after carbon black exposure. Acta Medica Lugoslavica 1980; 34: 363-372.

21. Gardiner $\mathrm{K}$, Calvert IA, van Tongeren MJA, Harrington JM. Occupational Exposure to carbon black in its manufacture: Data from 1987 to 1992. Ann Occup Hyg 1996; 40: 65-77.

22. van Tongeren MJA, Kromhout H, Gardiner K. Trends in levels of inhalable dust exposure, exceedance and overexposure in the European carbon black manufacturing industry. Ann occup Hyg 2000; 44: 271-280.

23. Medical Research Council. Questionnaire on respiratory symptoms. London, Medical Research Council, 1986.

24. International Labour Organisation. Guidelines for the use of ILO international classification of radiographs of pneumoconiosis. Revised edition 1980. Occupational Safety and Health series No. 22 (Rev). Geneva, ILO, 1980.

25. Morgan WKC. Epidemiology and occupational lung disease. In: Morgan WKC, Seaton A, eds. Occupational Lung Diseases. 3rd edn. Philadelphia, W.B. Saunders Company, 1995; pp. 82-110.

26. van Tongeren MJA, Gardiner K. Determinants of inhalable dust exposure in the European carbon black manufacturing industry. Appl Occup Environ Hyg 2001; 16: 237-245.
27. Mark D, Vincent JH. A new personal sampler for airborne total dust in workplaces. Ann Occup Hyg 1986; 30: 89-102.

28. Quanjer PH, Tammeling GJ, Cotes JE, Pederson OF, Peslin R, Yernault JC. Lung volumes and forced ventilatory flows. Report working party standardisation of lung function tests European Community for Steel and Coal. Official statement of the European Respiratory Society. Eur Respir J 1993; 6: 5-40.

29. American Thoracic Society. Standardization of spirometry - 1987 update. Am Rev Respir Dis 1987; 136: 1285-1298.

30. Harber P, Vormberg R, Merz B. Effect of production process on carbon black exposure. Eur Respir J 1999; 16: Suppl. 31, 27s.

31. Beck B, Gohlke R, Sturm W, Bergmann L, Wolf E. Carbon black lung as an occupational disease. Z Erkrank Atm-Org 1985; 164: 254-266.

32. Soutar CA, Miller BG, Gregg N, Jones AD, Cullen RT, Bolton RE. Assessment of human risks from exposure to low toxicity occupational dusts. Ann Occup Hyg 1997; 41: 123-133.

33. Oberdörster G, Ferin J, Gelein R, Soderholm S, Finkelstein J. Role of the alveolar macrophage in lung injury: studies with ultrafine particles. Environ Health Perspect 1992; 97: 193-199. 